\title{
A Review on Natural Antioxidants in Foods and New Insights on Animal Body Compounds, Role, Production and Future Perspectives
} \author{
Talat Sabtain ${ }^{6}$, Abid Hussain ${ }^{7}$ \\ ${ }^{1}$ Department of Biochemistry, University of Agriculture, Faisalabad, Pakistan \\ ${ }^{2}$ National Institute of Food Science and Technology, University of Agriculture, Faisalabad, Pakistan \\ ${ }^{3}$ Department of Biochemistry, Government College Women University, Faisalabad, Pakistan \\ ${ }^{4}$ Department of Zoology, Government College University, Faisalabad, Pakistan \\ ${ }^{5}$ Deparment of Quality Assurance, Saffron Pharmaceuticals (Pvt Ltd), 19-km Sheikhupura Road, Faisalabad, Pakistan \\ ${ }^{6}$ Department of Zoology, Wildlife and Fisheries, University of Agriculture, Faisalabad, Pakistan \\ ${ }^{7}$ Department of Agronomy, University of Agriculture, Faisalabad, Pakistan
}

Hafiza Memoona Asif ${ }^{1}$, Umair Ishfaq $^{2 *}$, Saadia Sohail ${ }^{3}$, Muhammad Izhar ${ }^{4}$, Hamza Rafeeq $^{1}$, Muhammad Awais Hayder ${ }^{5}$,

DOI: $10.36348 /$ sjmps.2021.v07i01.004 $\quad$ | Received: 13.12 .2020 | Accepted: 21.12 .2020 | Published: 11.01 .2021

*Corresponding author: Umair Ishfaq

\section{Abstract}

Carbohydrates are present in the form of starch and sugars in our food. The three major antioxidant vitamins are betacarotene, vitamin $\mathrm{C}$, and vitamin $\mathrm{E}$. Beta carotene, like all carotenoids, is an antioxidant also a scavenger of singlet oxygen. The main cause of vitamin $\mathrm{C}$ loss from food is leaching, which transfers vitamin $\mathrm{C}$ to the cooking water, which is decanted and not consumed. Vitamin E is found naturally in some foods, added to others, and available as a dietary supplement. The blood of the animals also contains the various clotting factors that significantly involved in the processes or events related the blood cancer or diseases. The major type of the protein in the system of vertebrate in the blood is the fibrinogen. The blood of the human also contains the various clotting factors that significantly involved in the processes or events related the blood cancer or diseases. The thrombolytic activity of the food extracts remains unclear and not completely studied yet. Different factors are involved in clotting of the blood. Different compounds in foods promoted the clotting of the blood by activating the calcium. This review helpful for the investigation of the novel compounds in many plants that are used to treat the large number of diseases as well as to understand the nature of compounds that reduce the production of the free radicals in the particular cells.

Keywords: Carbohydrates, Proteins, Vitamins, Animal blood, Animal fibrinogen.

Copyright (C) 2021 The Author(s): This is an open-access article distributed under the terms of the Creative Commons Attribution 4.0 International License (CC BY-NC 4.0) which permits unrestricted use, distribution, and reproduction in any medium for non-commercial use provided the original author and source are credited.

\section{INTRODUCTION}

Carbohydrates are present in the form of starch and sugars in our food. Presence of fat in food is indicated when food wrapped in paper turns oily after releasing its moisture content The three major antioxidant vitamins are beta-carotene, vitamin $\mathrm{C}$, and vitamin E. Beta carotene, like all carotenoids, is an antioxidant. $\beta$-Carotene is a strong antioxidant and also a scavenger of singlet oxygen. Scurvy is a disease resulting from a deficiency of vitamin $\mathrm{C}$ [1].

Another cause of vitamin C loss from food is leaching, which transfers vitamin $\mathrm{C}$ to the cooking water, which is decanted and not consumed. Vitamin $\mathrm{E}$ is found naturally in some foods, added to others, and available as a dietary supplement [2,3]. Vitamin E supplementation in infants might reduce the risk of some complications, such as those affecting the retina, but they can also increase the risk of infections.
Platelets are the type that are present in cells of blood. When vessels present in the bloods broken normally that leads to activation of the platelets by a certain stimuli which are present in the blood. When platelets become activate that initiates a process in the blood called aggregation of platelets. When there is more platelets to be activated that also causes the thrombosis [4].

The blood of the animals also contains the various clotting factors that significantly involved in the processes or events related the blood cancer or diseases. The process of the clotting in biochemical ways involved the process of the coagulation in the blood [5, 6]. These have taken important value in the process of the clotting. RBCs of the blood has multiple functions in the body but the most important performed by them to the transport of the gases such the oxygen as well as 
the carbon dioxide. The major type of the protein in the system of vertebrate in the blood is the fibrinogen [7].

\section{Composition of Food}

The presence of carbohydrates in food can be tested using a dilute iodine solution, an indication of the presence of starch is shown by black-blue colouration. Presence of protein in food is tested using a solution of copper sulphate and caustic soda. If the solution turns violet, proteins are present [8].

Table-1: Shows nature the antioxidants and their sources

\begin{tabular}{ll} 
Exogenous antioxidants & Dietary sources \\
\hline $\begin{array}{l}\text { Vitamin C } \\
\text { (ascorbic acid/ascorbate) }\end{array}$ & $\begin{array}{l}\text { Bell peppers, strawberries, kiwi, } \\
\text { Brussels sprouts, broccoli }\end{array}$ \\
$\begin{array}{l}\text { Vitamin E (tocopherols, } \\
\text { tocotrienols) }\end{array}$ & $\begin{array}{l}\text { Vegetable oil and its derivatives } \\
\text { (margarine, salad dressing), nuts, } \\
\text { seeds }\end{array}$ \\
$\begin{array}{l}\text { Carotenoids ( } \alpha \text {-carotene, } \\
\beta \text {-carotene, zeaxanthin, } \\
\text { lutein, lycopene, }\end{array}$ & $\begin{array}{l}\text { Orange and red vegetables and } \\
\text { fruits (carrots, tomatoes, apricots, } \\
\text { plums) and green leafy vegetables } \\
\text { (spinach, kale) }\end{array}$ \\
$\begin{array}{l}\text { Polyphenols (flavonols, } \\
\text { flavanols, anthocyanins, } \\
\text { isoflavones, phenolic } \\
\text { acid) }\end{array}$ & $\begin{array}{l}\text { Fruits (apples, berries, grapes), } \\
\text { vegetables (celery, kale, onions), } \\
\text { legumes (beans, soybeans), nuts, } \\
\text { wrace elements (selenium, tea, coffee, cocoa }\end{array}$ \\
$\begin{array}{l}\text { zinc) } \\
\text { wing }\end{array}$ & Seafood, meat, whole grains
\end{tabular}

\section{Role of Beta-carotene as source of Foods}

Beta carotene, like all carotenoids, is an antioxidant. An antioxidant is a substance that inhibits the oxidation of other molecules; it protects the body from free radicals. Some studies have suggested that those who consume at least four daily servings of beta carotene rich fruits and/or vegetables have a lower risk of developing cancer or heart disease. It is also a provitamin $A$ as it can be converted into retinol. In commercial cherry tomato varieties, $\beta$-carotene content reached $1.2 \mathrm{mg}$ per $100 \mathrm{~g} \mathrm{FW}$. Bioaccessibility of $\beta$ carotene from raw tomatoes was reported to be about $0.1 \%$. Studies demonstrated the photoprotective effects of $\beta$-carotene on photooxidative damage and sunburn in humans $[9,10]$.

\section{Role of Vitamin C in Foods}

Vitamin C or ascorbic acid (AsA) is a naturally occurring organic compound with antioxidant properties, found in both animals and plants. Without this vitamin, collagen made by the body is too unstable to perform its function and several other enzymes in the body do not operate correctly. Vitamin $\mathrm{C}$ chemically decomposes under certain conditions, many of which may occur during the cooking of food. Vitamin $\mathrm{C}$ concentrations in various food substances decrease with time in proportion to the temperature at which they are stored. Cooking can reduce the vitamin $\mathrm{C}$ content of vegetables by around $60 \%$, possibly due to increased enzymatic destruction. Longer cooking times may add to this effect $[11,12]$.

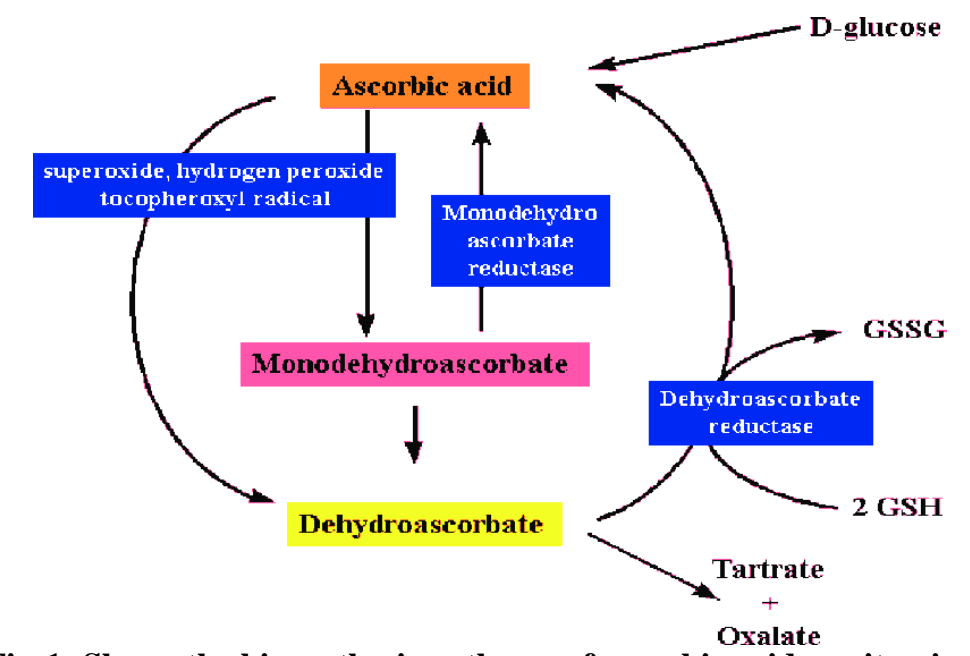

Fig-1: Shows the biosynthesis pathway of ascorbic acid or vitamin C 


\section{Role of Vitamin $E$}

"Vitamin E" is the collective name for a group of fat-soluble compounds with distinctive antioxidant activities. Naturally occurring vitamin E exists in eight chemical forms (alpha-, beta-, gamma-, and deltatocopherol and alpha-, beta-, gamma-, and deltatocotrienol) that have varying levels of biological activity vitamin E deficiency is rare and overt deficiency symptoms have not been found in healthy people who obtain little vitamin $\mathrm{E}$ from their diets . Premature babies of very low birth weight $(<1,500$ grams) might be deficient in vitamin E. Vitamin E supplementation in these infants might reduce the risk of some complications, such as those affecting the retina, but they can also increase the risk of infections $[13,14]$.

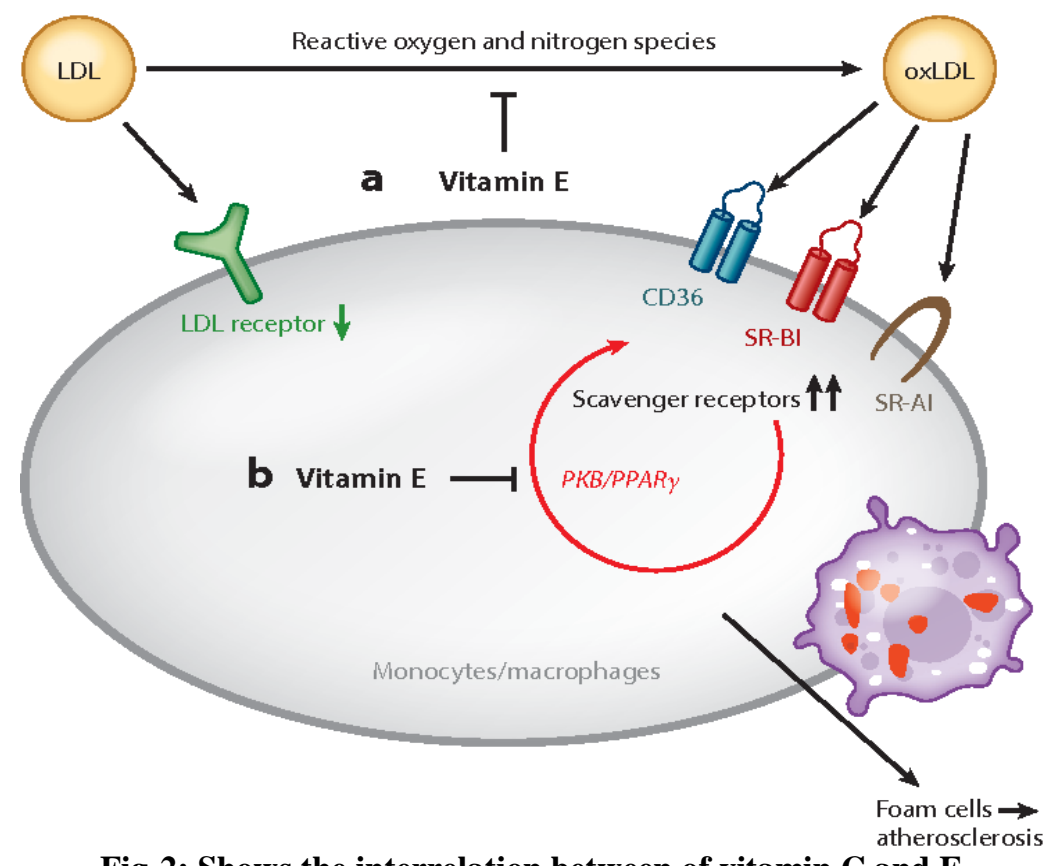

Fig-2: Shows the interrelation between of vitamin $C$ and $E$

\section{Role of Chemical compounds in Animal studies}

A study of the dogs demonstrated that juice of the food antioxidants decreased the reduced aggregation of platelets due to presence of compounds in the onion called flavonoids especially quercetin. There are certain benefits of using onion in the diet. It has antioxidants that are helpful in the prevention of disease such as coronary thrombosis that causes clot in the vessels of blood, and to prevent atherosclerosis. Particularly, onion has been used in a study to reduce aggregation of platelet by a variety of agonists in vitro and in vivo.

The significance of the factors that directly involved in the process of the clotting reflected the phenomenon of separation as well as laboratory purification of the factors. Some of the recent research scientifically showed that if one of the component or factor that makes the significant portion of the blood lacking, then certain modification occurs in the system as studies in vitro. These studies reflected the other image of the factor that involved in the clotting by growing them in the laboratory. If any of the patient needs the factors or demands, then artificially prepared factors in the synthetic experiments based the laboratories would work effectively. But this little or no permanent solution for the long or prolong period to meet the all reaction carry of the body in a right direction for the synthesis of the different compounds formed in the process of the metabolism $[15,16]$.

Previous studies showed that three clotting factors of the blood that significantly involved in the process of the clotting. These included most effective and biologically part of the blood that makes the full composition of the blood is the fibrinogen or the type I. This factor mainly the primary or basic factor due to which the all reaction of the clotting depends in a synergistically with biochemical to the each other. If this factor is missing in the blood, then the process of the coagulation would not be occurs and all of the important events that would be occurs and not given a response from the type of the factor. The other part of the blood involved in the process of the clotting mainly prothrombin or type II of the factor. This type or part of the blood that makes the significant composition of the blood. The last or least important parameter or factor in the process of the clotting mainly the hemophilia A, II VIII. These have much more the taken important value in the process of the clotting $[17,18]$.

\section{Animal body clotting compounds and their role}

The main clotting types of the factors that significantly much involved in the biochemical nature of the clotting help to control the bleed areas as well as then then repairs them in terms of the biochemistry as 
investigated in the experiments would performed by the scientists. If any of the important and mandatory factor that significantly involved in the clotting, then overall changes would appears biochemically, there are then chances to bleeding that areas in which severe of the bleeding occurs, chances of the cancer of the of the blood occurs [19, 20].

When more of the free radicals in the body, these readily attack on the RBCs which finally cannot supply the oxygen to the different parts of the body [21]. The red types of the onions contains more of the flavonoids and more of the supply of the oxygen to the body. The white type of the onions contain fewer amounts of the flavonoids and less of the supply of the oxygen to the body. It leads to the deaths of the RBCs due to the more of the stressed faced by the cells of the blood. It is important to keep use the onions in the diet as mandatory part of the food to prevent the cells of the body from the cancer as well as the other diseases such as cardiovascular [22].

The blood of the human also contains the various clotting factors that significantly involved in the processes or events related the blood cancer or diseases. The blood of the human gets punctured due to the injury as well as the serious events, then the process started that continues the blood allow effectively releasing the blood from the veins from of body of the human $[23,24]$. Major type of the leakage in the veins of the body of the human, then there is need to sealed the important and vendor veins of the body of the human. Previous data reported that biochemical types of the leakage of the events that majorly occurring in the blood. If there small leakage or small amount of the blood releases from the main and mandatory part of the veins, then system of the body would also take the major action to supply the blood to the injured areas. But major events that seen in the history of the past that causes the majorly occurring severe types of the deaths of the human [25].

Previous studies reported that severe form of the disease associated to the clotting factor included the hemophilia. When this disease occurs at the most advanced and alarming stage, then means any of the factor that is involved in the clotting is mistakenly missing in the blood or might not be work possible due to severe defect in the protein. When very low formation of the clotting occurs, then the chances for the hemophilia would be occurs in a way that leads to defects in the formation of the gene that is directly linked to the genetic level making of the body. When there no formation of the protein that linked to the process of the clotting, then there fewer chances of the factors that effectively work with to the special protein. Formation of proper clot important to keep fine and maintenance of the chemicals and other substances in the blood [26].
The most severe type of the hemophilia included the defect occured in the eight factor clotting. This type of the defect also the most dangerous for the formation of the clot formed in the cells of the body. This type of the factor would either transmitted through genetically from the group of the parents to the children by causing them a severe defect in the gene which ultimately causes the other defects in the factors that effective for the formation of the clots. Some of the studies in the laboratories investigated that the factor that is produced artificially by the scientists would useful for the short time of the period and not taken for the longer period. It might be the change occurs in the cells of the blood at the genetic formation occurs in growth of the baby, then DNA might be lost some of the characters that are important for the formation of the clotting. In some of the experimental studies in rats for investigation of the clotting experiments, clotting occurs in the cells but not longer time at the level of the cell [27].

\section{Role of Animal Fibrinogen}

Fibrinogen protein that directly involved to the formation of the clot. It also takes the greater advantage as compared to the other group of the proteins as it possess glycoprotein nature that makes the suitable complex with the special types of the carbohydrates. Once the fibrinogen formed in the cells of the blood or its formation predominantly formed in the cells of the liver, then synthesis of the clotting would started in the whole of the blood. Then, it circulated to the different routes from blood to the various parts of the body. These have much more the taken important value in the process of the clotting. It is also directly targeted to cells of the harmful attacked to the liver. It makes the clot when there is an injury occurs and need to clot the blood [28].

The other major type of the factor that directly involved in the process of the clotting mainly the prothrombin. These included the most effective and biologically part of blood that makes the full composition of the blood [29-32]. Its formation also occurs in the cells of the liver. If the liver damage as well as injured due to the chemicals and the attacks of the harmful viruses occurred, then this type of the factor not properly synthesized in the cells of the liver due to more formation of the harmful substances in the participation of the liver. If this type of protein not synthesized in the cells of the liver, then the process of the clotting would takes the longer the time for going to the situation of the clotting. Formation of proper clot is very important to keep fine and maintenance of the chemicals and other substances in the blood. It is the only possible when this type of the factor working in the liver for taking the proper action of clotting [32-35]. 


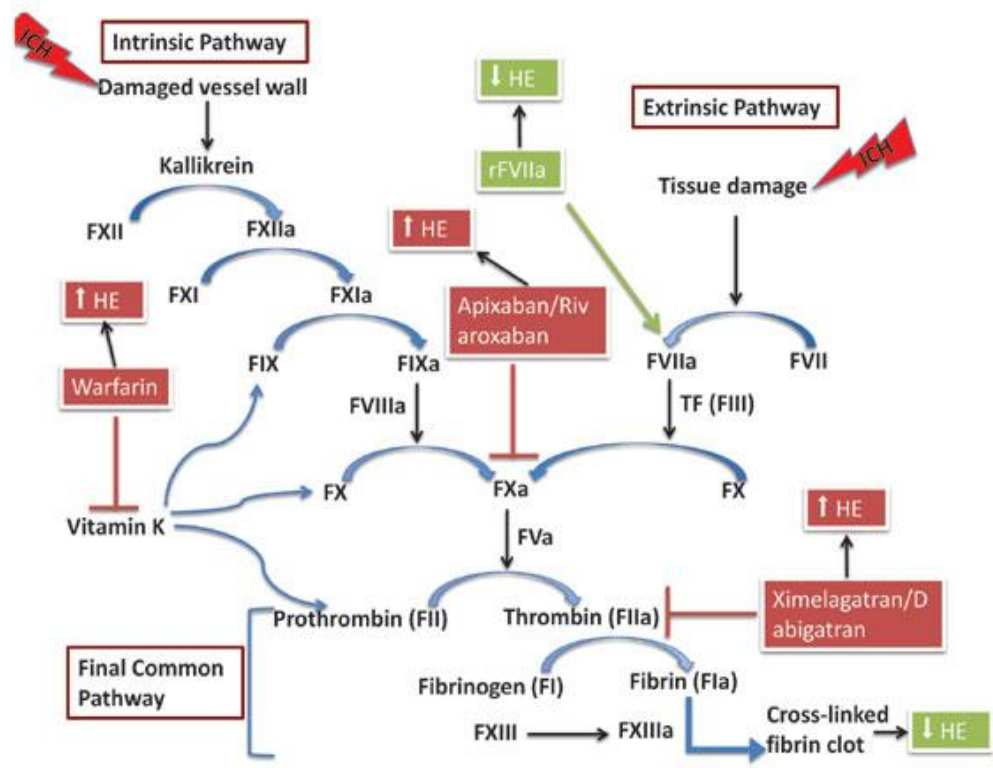

Fig-3: Shows the steps involved in animal blood clotting

\section{CONCLUSION}

There are many diseases that have been treated by the using the medicinal plants. These diseases included the cancers, diabetes and many inflammatory diseases. These diseases are not completely treated yet with the medicines that are used as the chemicals. Many plants contain variety of compounds such as the flavonoids that are not completely studied. This review article helpful for the investigation of the novel compounds in many plants that are used to treat the large number of diseases as well as to understand the nature of compounds that reduce the production of the free radicals in the particular cells.

\section{REFERENCES}

1. Shahidi, F. (2000). Antioxidants in food and food antioxidants. Food/nahrung, 44(3), 158-163.

2. Namiki, M. (1990). Antioxidants/antimutagens in food. Critical Reviews in Food Science \& Nutrition, 29(4), 273-300.

3. Pokorný, J. (1991). Natural antioxidants for food use. Trends in Food Science \& Technology, 2, 223-227.

4. Shahidi, F. (Ed.). (1997). Natural antioxidants: chemistry, health effects, and applications. The American Oil Chemists Society.

5. Shahidi, F., \& Ambigaipalan, P. (2015). Phenolics and polyphenolics in foods, beverages and spices: Antioxidant activity and health effects-A review. Journal of functional foods, 18, 820-897.

6. Taghvaei, M., \& Jafari, S. M. (2015). Application and stability of natural antioxidants in edible oils in order to substitute synthetic additives. Journal of food science and technology, 52(3), 1272-1282.

7. Naeem, M., Hayat, M., Qamar, S. A., Mehmood, T., Munir, A., Ahmad, G., ... \& Hussain, A. (2019). Risk factors, genetic mutations and prevention of breast cancer. Int. J. Biosci, 14(4), 492-496.

8. Shafiq, S., Adeel, M., Raza, H., Iqbal, R., Ahmad, Z., Naeem, M., ... \& Azmi, U. R. (2019). Effects of Foliar Application of Selenium in Maize (Zea Mays L.) under Cadmium Toxicity. In Biological Forum-An International Journal (Vol. 11, No. 2, pp. 27-37).

9. Ahmad, I., Khan, S., Naeem, M., Hayat, M., Azmi, U. R., Ahmed, S., ... \& Irfan, M. (2019). Molecular Identification of Ten Palm Species using DNA Fingerprinting. Int. J. Pure App. Biosci, 7(1), 46-51.

10. Embuscado, M. E. (2015). Spices and herbs: Natural sources of antioxidants-a mini review. Journal of functional foods, 18, 811-819.

11. Roleira, F. M., Tavares-da-Silva, E. J., Varela, C. L., Costa, S. C., Silva, T., Garrido, J., \& Borges, F. (2015). Plant derived and dietary phenolic antioxidants: Anticancer properties. Food Chemistry, 183, 235-258.

12. Galano, A., Mazzone, G., Alvarez-Diduk, R., Marino, T., Alvarez-Idaboy, J. R., \& Russo, N. (2016). Food antioxidants: chemical insights at the molecular level. Annual review of food science and technology, 7, 335-352.

13. Aguiar, J., Estevinho, B. N., \& Santos, L. (2016). Microencapsulation of natural antioxidants for food application-The specific case of coffee antioxidants-A review. Trends in Food Science \& Technology, 58, 21-39.

14. Ganiari, S., Choulitoudi, E., \& Oreopoulou, V. (2017). Edible and active films and coatings as carriers of natural antioxidants for lipid food. Trends in Food Science \& Technology, 68, 70-82.

15. Hasson, S. S., Al-Shaqsi, M. S., Albusaidi, J. Z., Al-Balushi, M. S., Hakkim, F. L., Aleemallah, G. 
M., \& Al-Jabri, A. A. (2018). Influence of different cultivars of Phoenix dactylifera L-date fruits on blood clotting and wound healing. Asian Pacific Journal of Tropical Biomedicine, 8(7), 371.

16. Gehrke, S. A., Dedavid, B. A., Aramburú, J. S., Pérez-Díaz, L., Guirado, J. L. C., Canales, P. M., \& De Aza, P. N. (2018). Effect of Different Morphology of Titanium Surface on the Bone Healing in Defects Filled Only with Blood Clot: A New Animal Study Design. BioMed research international, 2018.

17. Usman, G., Muhammad, N., Hamza, R., Usman, I., Ayesha, A., Saqib, U., ... \& Fatima, Q. (2019). A Novel Approach towards Nutraceuticals and Biomedical Applications. Scholars International Journal of Biochemistry, 2(10), 245-252.

18. Naeem, M., Ali, J., Hassan, M. Z., Arshad, B., Rao, M. H. I., Sarmad, M. S. K., ... \& Hussain, M. U. Novel Approach towards DNA Barcoding as a Tool in Molecular Biology and Biological Activities of Cyclotides with Particular Emphasizes at Molecular Level.

19. Naeem, A., Saddique, S., \& Chand, S. A. (2019). Advancement and Future Directions towards Herbal Treatment for Various Diseases.

20. Naeem, M., Ashraf, A., Safdar, H. M. Z., Khan, M. Q., Rehman, S. U., Iqbal, R., ... \& Ahmad, G. Biochemical changes in patients with chronic kidney failure in relation to complete blood count and anemia.

21. Naeem, M., Hussain, A., Azmi, U. R., Maqsood, S., Imtiaz, U., Ali, H., ... \& Ghani, U. (2019). Comparative Anatomical Studies of Epidermis with Different Stomatal Patterns in Some Selected Plants Using Compound Light Microscopy. International Journal of Scientific and Research Publications, 9(10), 375-380.

22. Ahsan, M., Aslam, M., Akhtar, M. A., Azmi, U. R., Naeem, M., Murtaza, G., ... \& Shafiq, S. (2019). Effect of inoculation of three rhizobial strains on maize hybrids. Journal of Biodiversity and Environmental Sciences, 14(6), 168-177.

23. Hazafa, A., Batool, A., Ahmad, S., Amjad, M., Chaudhry, S. N., Asad, J., ... \& Ghani, U. (2020). Humanin: A mitochondrial-derived peptide in the treatment of apoptosis-related diseases. Life Sciences, 118679.

24. Khan, S., Abbas, A., Ali, I., Arshad, R., Tareen, M. B. K., \& Shah, M. I. (2019). Prevalence of overweight and obesity and lifestyle assessment among school-going children of Multan, Pakistan.

25. Rafeeq, H., Ahmad, S., Tareen, M. B. K., Shahzad, K. A., Bashir, A., Jabeen, R., ... \& Shehzadi, I. Biochemistry of Fat Soluble Vitamins, Sources, Biochemical Functions and Toxicity. Haya: The Saudi Journal of Life Sciences
26. Khan, S., Zelle Rubab, S. H., Abbas, A., Arshad, R., \& Tareen, M. B. K. Hematological profile of children with severe acute malnutrition at the Tertiary care hospital in Multan.

27. Shahid, A., Ali, S., Zahra, T., Raza, M., Shahid, A., Saeed, M. U., \& Javaid, F. 2020. Influence of Microbes in Progression of Cancer and DNA Damaging Effects. Haya: The Saudi Journal of Life Sciences

28. Iftikhar, A., Shahid, A., Shah, S. S., Ali, S., Raza, M., Ali, E., \& Umbreen, S. Antimicrobial Activities of Selected Medicinal Plant with Potential Role of Chemical Compounds. Haya: The Saudi Journal of Life Sciences

29. Sato, A., Nakazawa, K., Sugawara, A., Yamazaki, Y., \& Ebina, K. (2018). The interaction of $\beta 2$ glycoprotein I with lysophosphatidic acid in platelet aggregation and blood clotting. Biochimica et Biophysica Acta (BBA)Proteins and Proteomics, 1866(12), 1232-1241.

30. Barrett, C. D., Hsu, A. T., Ellson, C. D., Y. Miyazawa, B., Kong, Y. W., Greenwood, J. D., ... \& Cohen, M. J. (2018). Blood clotting and traumatic injury with shock mediates complement- dependent neutrophil priming for extracellular ROS, ROS- dependent organ injury and coagulopathy. Clinical \& Experimental Immunology, 194(1), 103-117.

31. Hindmarch, S., Rattner, B. A., \& Elliott, J. E. (2019). Use of blood clotting assays to assess potential anticoagulant rodenticide exposure and effects in free-ranging birds of prey. Science of the Total Environment, 657, 1205-1216.

32. Rodrigues, M. S., Lima, L., das Chagas Xavier, S. C., Herrera, H. M., Rocha, F. L., Roque, A. L. R., ... \& Jansen, A. M. (2019). Uncovering Trypanosoma spp. diversity of wild mammals by the use of DNA from blood clots. International Journal for Parasitology: Parasites and Wildlife, 8, 171-181.

33. Li, Z., Milionis, A., Zheng, Y., Yee, M., Codispoti, L., Tan, F., ... \& Yap, C. H. (2019). Superhydrophobic hemostatic nanofiber composites for fast clotting and minimal adhesion. Nature communications, 10(1), 1-11.

34. Fan, Q., Ma, Q., Bai, J., Xu, J., Fei, Z., Dong, Z., ... \& Wang, C. (2020). An implantable blood clotbased immune niche for enhanced cancer vaccination. Science advances, 6(39), eabb4639.

35. Koumentakou, I., Terzopoulou, Z., Michopoulou, A., Kalafatakis, I., Theodorakis, K., Tzetzis, D., \& Bikiaris, D. (2020). Chitosan dressings containing inorganic additives and levofloxacin as potential wound care products with enhanced hemostatic properties. International Journal of Biological Macromolecules, 162, 693-703. 